\title{
STRATEGIC PLANNING AND RESOURCE ALLOCATION FOR A SUSTAINABLE DEVELOPMENT IN A DEVELOPING COUNTRY
}

\author{
Measuring Benefits, Costs, and Risks in a Social, Economical and Environmental Frame \\ Claudio Garuti A. \\ Fulcrum Ingeniería Ltda. \\ claudiogaruti@fulcrum.cl
}

\begin{abstract}
For society in the last years the idea of sustainable business has become a very important idea considering both sides view, the necessary inside developing of the business as well as the surrounding environment where is located. The different social organizations like communities, workers, families, and stakeholders, have understand the importance that business or entrepreneurships of certain level take care of their possible environmental, social and economical impacts, considering the two basic aspects for the "responsibility" concept, that is presenting the accountability of the business in front of their stakeholders and at the same time be able to respond to the different social organizations about his behavior, put together these two aspects it necessary carry into the Corporative Social Responsibility (CSR) concept, it means to look the business and its surrounding as a whole indivisible. This new approach takes the concept of sustainable development into the core of the business; this was the case of the Mining Company "Los Pelambres” in Chile (a developing Country). The Company has incorporated in his core business the concept of CSR using the triple view scheme (economic, social and environmental view) to design his strategy of resource allocation and projects assessment. To do this task considering the multiple actors that have to participates in the process, with different (even contra post) point of view, different data, units and type of information, it became necessary to apply the analytic Hierarchy Process (AHP) for the analysis and modeling process, incorporating from the very beginning of the business the visions of the stakeholders to measure the global impact of almost all the projects (the actions) of the Company.
\end{abstract}

Keywords: Sustainable Development, Corporative Social Responsibility, Resource allocation, AHP, Benefits, Costs and Risks.

\section{INTRODUCTION}

The mining Company Minera Los Pelambres (MLP) works in a developing Country, in an environments which is different from other mining companies. It is located at 3.600 meters of altitude in the Cordillera de los Andes, in the locality of Salamanca in the Choapa Province of Coquimbo Region, circa $400 \mathrm{Km}$ at north of Santiago (Chile). The mine installation and services goes from Cordillera to the Pacific ocean on the port of Punta Chungo close to Los Vilos, including more than 40 communities and 80 thousand people along this mining way (see figure1: geographic location) 


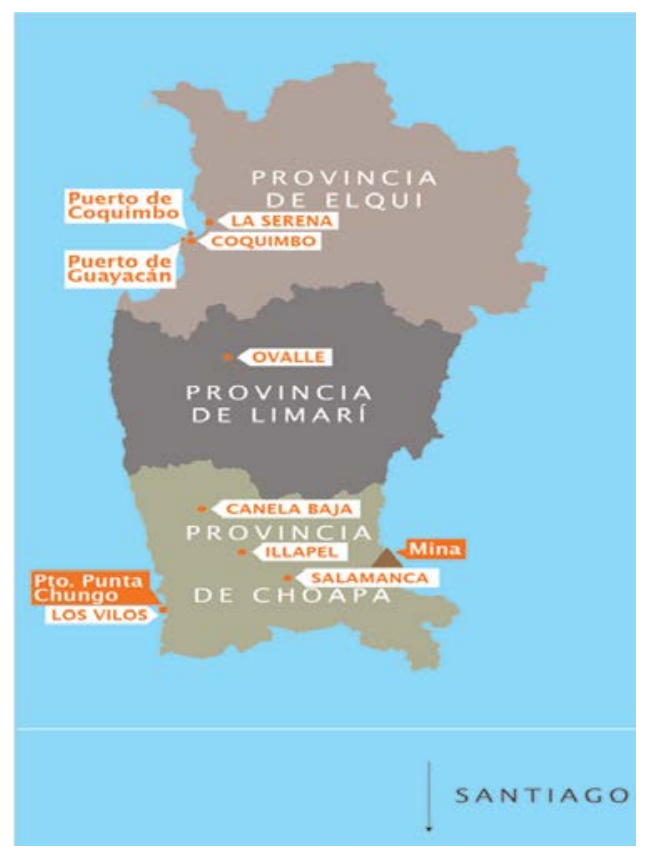

Figura1: Geographic location

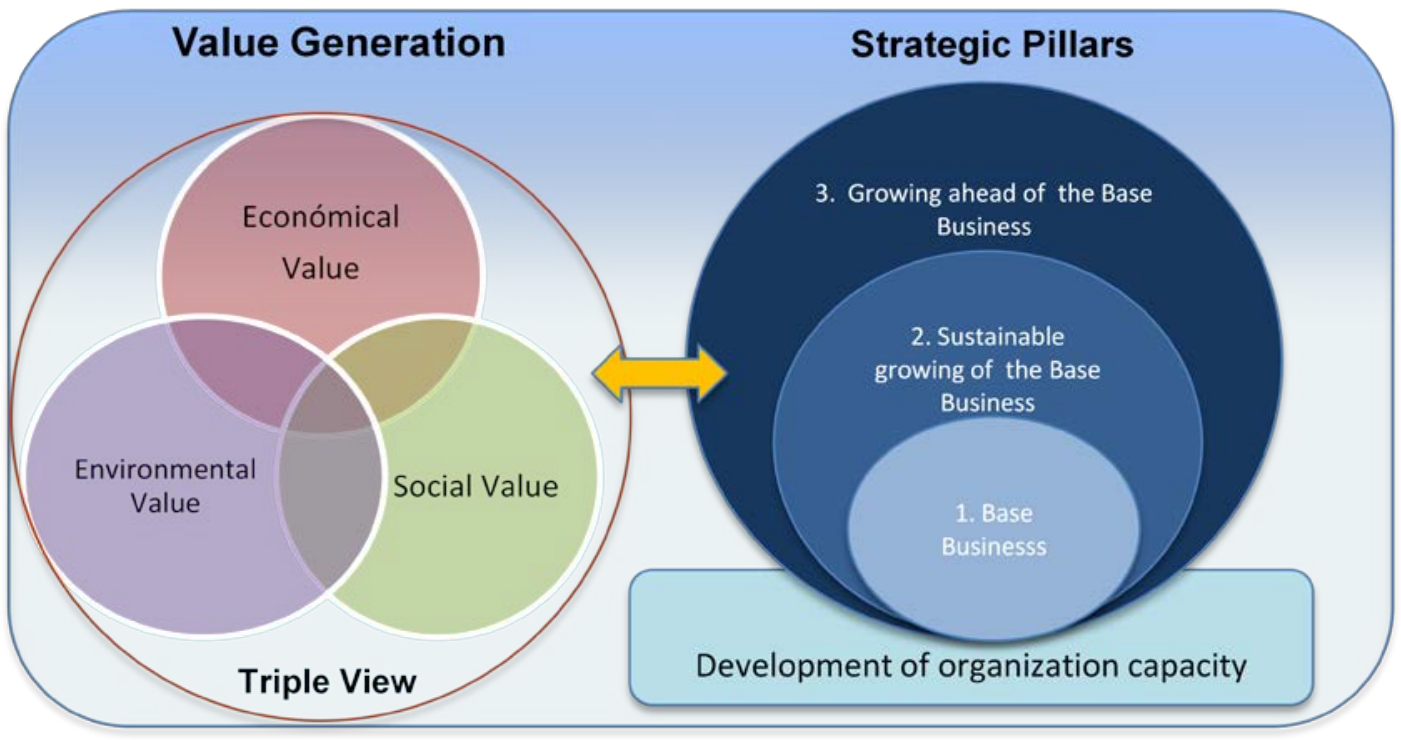

Figure2: Company strategy for value generation

As a Company, we worked on a prioritization model of the investment portfolio under the triple perspective with about 25 different stakeholders, in order to align the investments of the Company with the strategy, particularly with its vision and mission, through a model to solve complex problems of multiple criteria. For this, firstly is necessary a clear definition of the overall objective of the MLP and the specific objectives of the work to develop.

Thus, the final objective of this work is: "Maximizing the sustainable value generation in all investments of the Company". Through the following specific objectives:

1. - Prioritize the projects portfolio to perform each year, ensuring operational continuity in a sustainable way.

2. - Involve the entire company in the investments alignment process with the strategic objectives of the company. 
3. - Correctly assign the resources for the investments perform, giving priority to those that generate greater sustainable value.

On the other hand, it is important to know the technical requirements that will be generated from the specific objectives to choose the right model to perform the task. The model should be able to:

Incorporate quantitative and qualitative variables in the evaluation of the sustainable value creation of our investments.

Organize efficiently and graphically the information about a problem.

Break down and analyze the information in parts.

Display and summarize the changes effects in the different levels of the model.

Hand multiple stakeholders and objectives.

Generation of a measurement rule (a metric) shared by the stakeholders

Here is where the AHP (Analytic Hierarchy Process) method comes into play. The $\mathrm{AHP}^{7,8}$ is a multicriteria methodology corresponding to a "metric engine" and allows build the overall performance measurement of the business from 3 different perspectives or different decision models, these are: Benefits, Costs and Risks. Within each of these perspectives it is incorporated the concept of the 3 traditional views (triple view) of corporate social responsibility, that is, the economic , social and environmental point; getting a full measure rule of the business formed from a BCR perspective, i.e.: economic, social and environmental benefits; costs and risks. It should be noted that this structure makes it possible to analyze the problem from the perspective of the benefits which pillars that constitute the triple view (social, economic and environmental view), may have a particular weighting for benefits, other for costs and other more for risks, thus, for example, the logical situation in which economics aspects can be more relevant on the benefits model than the costs or risk, or socio-environmental aspects be more relevant in the perspective of the costs or the risks than the possible benefits.

\section{DATA/MODEL ANALISYS}

While there is some consensus on the importance of CSR in the current situation most of the companies are unclear about how to measure the real impact of their CSR strategy in social, environmental and economical terms.

Most companies only accumulate anecdotes about uncoordinated initiatives to show social and environmental sensibility of the Company and present them in their sustainability reports.

(Eduardo Mizon, General Manager of "Accion-RSE", the Chilean Association for CSR, interview for El Mercurio, June-2013 \& M. Porter and M. Kramer, Strategy and Society).

In terms of accountability, companies normally only respond against its stakeholders regarding the amount of money and hours of time invested, but not in terms of how they affect society, i.e. accountancy is performed from money and effort invested and not in terms of results.

In short, today companies do not know the real effects that a given project will from economic, social and environmental points of view; this may leads to not having a real strategy as a Company or at least not to have an effective and measurable one. (M. Porter and M. Kramer, Strategy and Society). But why is it so important to measure correctly?

ISO 26000 and OCDE require to the measurements companies in social responsibility initiatives.

We require a reliable measurement of the variables to determine the relevance of the strategies of CSR and the degree of alignment with the impacts of the value chain of the Company.

Good business decisions require good information from reliable measurements.

Measurements facilitate transparency to account to society. Companies must demonstrate results and impact of their CSR. This point is directly related to another that is essential for successful implementation of CSR strategy that is "accountability".

The measurements allow tracing the implementation of the decisions and CSR policies. There is no Management if there is no Measurement (Peter Drucker) 
The importance of building a well-established metric, is of enormous potential for a correct analysis and synthesis process, without a work platform like AHP that handle multiple criteria, multiple stakeholders, a structure view of relationships between parts and the construction of an appropriate metric, it would be very difficult (if not impossible) to get a finished product at the level of complexity required to correctly address the problem and at the same time to be easy for implementation at the different levels of the Company.

Spite of is not possible to share the AHP models due to confidential issues, it will be shown the strategy behind (figure 4)

The figure above is the list of 38 terminal criteria that are take it in account to prioritize the benefits of the set of projects, they are ranked in alphabetical order. By the other hand, there is $25+50$ others terminal criteria associated to Costs and Risks models, totalizing 113 terminal criteria for the 3 models. So, it can be said that any project of the portfolio will be analyzed deeply and evaluated in terms of its own capacity to satisfy the Company strategy from economical, social and environmental view under the 3 perspectives, as it will be explained next in figure6: "the paradigm shift”.

The measurement criteria of each model are analyzed through the prism of the priorities of the Company and stakeholders, building a prioritized set of values (the value system of the Company and its stakeholders), representing the Company's strategy.

As explained in the introduction, the importance of measuring correctly is essential if one want to have an adequate accountability and also to assess the alignment of the strategy developed with the results obtained in the implementation of the investment (the portfolio investment projects), in this way the AHP models are directly connecting cause and effect in terms of measurement, under the triple perspective (see Figure4 "Paradigm Shift"), obtaining as output three portfolios prioritized under a cardinal type of measurement for benefits, costs and risks.

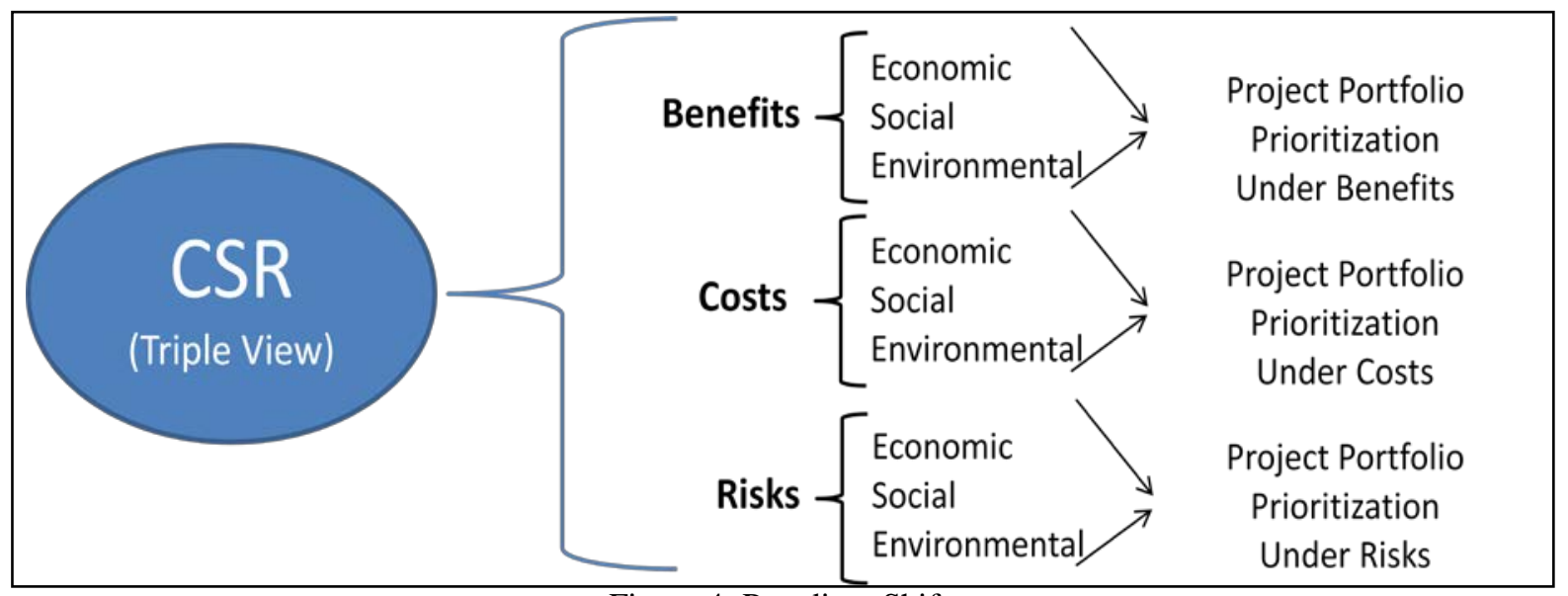

Figure 4: Paradigm Shift

LIMITATIONS (FUTURE CHALLENGES):

Considering the great value that the Mining Company Los Pelambres gave to this project, it outlined the following future challenges:

- Applying the methodology to the investment portfolio every year (implementation and use of the system), measuring their alignment with strategy and feeding back of results to maintain and / or improve the alignment with the strategy over time.

- Generate a tool that involves the entire Company comprehensively in sustainability (the triple view).

- Diffuse into interest groups the model to be applied (socializing processes and results). 
- Install this kind of decision making process in others business line of the Company like selection of suppliers or people assessment for promotion.

\section{CONCLUSIONS:}

The main conclusions and lessons learned from this study are related to four basic points:

1. Build an interactive and integrative process for the different views of the Stakeholders to generate decision models (Benefits, Costs and Risks) is essential. It is absolutely necessary to involve all parties into the decision process and to participate in the design of decision models from the beginning and from their different perspectives, to add the knowledge and relevant information they hold to the model ${ }^{9}$.

2. Measuring the impact of different application areas of a project to evaluate properly the alignment between the Company strategy with its Stakeholders and also between them and the Community (overall accountability) ${ }^{1,2,3,4}$.

3. The principle of "accountability" is basic to any decision making process in CSR, without this principle all the money and / or effort (man-hours) committed would not have a sense of direction or strategy, would be like a car with tremendous power but without a wheel well assembled ${ }^{6}$.

4. The synergy development and a shared vision with the consultant team is vital to the development of the project and actually add value to the business, allowing the optimally use of the tool to facilitate the strategic decisions making process, such as: the models appropriate building, consistency check, impact assessment, scenario analysis, thresholds construction, alignment and compatibility analysis, search of optimality and others features that being relevant to the decision making process.

\section{KEY REFERENCES}

1) Garuti, C. A. Escudey \& M. (2005). Toma de Decisiones en Escenarios Complejos. Editorial Universidad de Santiago.

2) Garuti, C. A. (2007). Measuring compatibility (closeness) in weighted environments. Proceedings of the $7^{\text {th }}$ International Symposium on the AHP.

3) Garuti, C. A., \& Salomon, V. A. (2012). Compatibility Between priority index vectors. International Journal of AHP, 4, pp. 152-160.

4) Garuti, C. A. (2012) Measuring in Weighted Environments, Moving from Metric to Order Topology. ISBN: 978-956-7051-58-8. Editorial Universidad Federico Santa Maria.

5) Porter, Michael and Kramer, Mark, (2006) Strategy and Society - The link between competitive advantage and corporate social responsibility, Harvard Business Review, Reprint r0612d-e

6) Saaty, T. L. (1980). The Analytic Hierarchy Process. N. York: Mc-Graw-Hill. 